\title{
Study on Service Pricing of Third Party Logistics Service Platform of Railway Oil Supply Chain
}

\author{
Ruiping $\mathrm{Gao}^{1, \text { a }}$, Shouwen $\mathrm{Ji}^{1, \mathrm{~b}}$ and Liying Ding ${ }^{2, \mathrm{c}}$, Haitao Zhang ${ }^{2, \mathrm{c}}$ \\ ${ }^{1}$ MOE Key Laboratory for Urban Transportation Complex Systems Theory and Technology, Beijing \\ Jiaotong University, Beijing 100044, China; \\ ${ }^{2}$ CRM E-Commerce Tech. Co., Ltd, Beijing 100088, China;

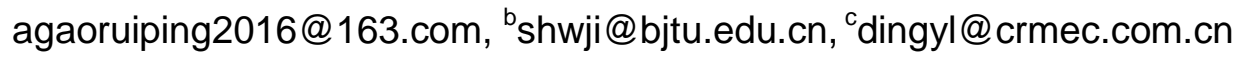

Keywords: Railway oil; logistics service platform; service pricing; oil supply chain.

\begin{abstract}
The paper analysis the influence factors of the third party logistics service platform of railway oil supply chain, finds oil usage amount is the most important pricing factor. Cost and benefit of the third service platform are analyzed, and feasible service price range of the platform is given. The bargaining game model is made to get the best single service price of the platform. Paper gives the empirical case to verify the feasibility of the model and algorithm.
\end{abstract}

\section{Introduction}

Currently, China's railway industry is in the transformation and development, and the logistics informatization has become the focus of development [1]. In 2014, CRM E-Commerce Tech. Co. ,Ltd and Beijing Jiaotong University researched out the third party logistics service platform of railway oil supply chain. Now the platform is free and it will charge with the maturity of the market in the future. At that time the service pricing will become an important issue which influences the benefits of the platform. Xinghua Wu studied the pricing of the regional logistics information platform based on the incentive Stackelberg game strategy [2], Yun Cong and Duan Mu studied the pricing strategy of the cloud services supply chain product [3]. This paper focuses on the information service pricing model of the third party service platform of the railway industry, and analyzes the actual operation data of the platform.

\section{Analysis of Influencing Factors of the Service Pricing of Third Party Logistics Service Platform of Railway Oil Supply Chain}

There are six main factors influencing the pricing of the third party service platform of the railway industry:

(1) Initial fixed investment and operation and maintenance cost of the platform

The platform operators will think of the payback period and investment profit margin when he considers the strategy of pricing of the platform.

(2) Marginal cost of the platform

Marginal cost of the platform generally refers to the increase cost of services led by the increase in the amount of information per unit. With the rapid development of information technology, the marginal cost of the platform is greatly reduced. In most literature studies, in order to facilitate research, the marginal cost of the platform is set to be zero.

(3) Number of users

In the early days of the operation, the platform often takes platform free strategy in order to attract users. With the growth of users, the platform begins to charge a certain fee.

(4) User willingness to pay

User's willingness to pay is used to measure the benefit (utility) of a project to a particular person, that is, in a situation how much does a person willing to pay. From a certain degree, it's equivalent to a utility function.

(5) User information usage

Unless the platform to adopt a fixed pricing strategy, how much fee the platform will charge the users is directly relevant to the amount of information they use. In addition, the pricing strategy will 
consider the user demand for value added services of the information platform. Normally, platform operators will adopt different pricing schemes for different user level.

\section{Research on the model of the Service Pricing of Third Party Logistics Service Platform of Railway Oil Supply Chain}

The pricing idea of the third party logistics service platform of railway oil supply chain is shown as the Fig. 1. It makes the platform pricing objectives and basis clear and grasps the overall direction before making strategy. Then it determines the lower limit of platform pricing is determined by the method of cost analysis according to the market economy theory, and it determines the upper limit of the platform pricing based on the platform for the user to bring the actual utility. Thus the reasonable pricing interval can be worked out. Based on the existing pricing model and theory, the optimal pricing is obtained through negotiation in this section [4].

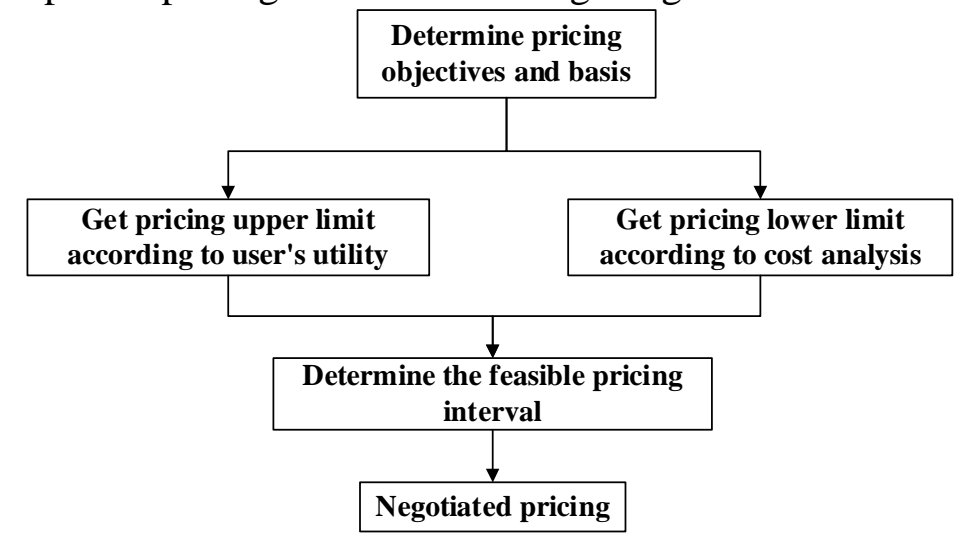

Fig. 1 The pricing idea of the third party logistics service platform of railway oil supply chain

\subsection{The Determination of the Usage Amount of Platform Information Service.}

Firstly, platform service pricing needs to be defined. Under normal circumstances, the usage amount of platform information service needs to be determined according to the amount of system operation. For example, the information platforms with data exchange as the main service function generally put the number of data exchange as the usage amount of platform information service.

The function of the third party service platform of railway oil supply chain is studied and analyzed based on the usage amount of railway oil. According to the survey data, in 2015, the usage amount of railway oil for 18 railway bureau users is positively correlated with the number of platform access.

Therefore, this paper selects the user's oil consumption as a measure of information service. For the railway bureau users with more usage amount of railway oil, the corresponding amount of operation data and information service are relatively more. Because there is a direct relationship between the benefit and the usage amount of railway oil, and the usage amount of railway oil is positively correlated with the number of platform access.

\subsection{The Determination of the Feasible Pricing Interval of Platform.}

(1) The determination of the lower limit of platform pricing based on cost analysis

For the sustainable development of the platform, this paper considers the pricing level from the platform investment recovery period. The total construction costs of the platform are mainly composed of the initial fixed investment costs $S$ and variable costs $R$. Fixed costs $S$ mainly include software development cost, hardware acquisition cost, and support software acquisition cost. Variable costs $R$ mainly include the platform operation and maintenance cost (assuming platform operation and maintenance cost as a fixed value) and platform marginal variable cost (due to the less volatility of the number of platform users, it is supposed that the platform marginal variable cost is zero).

Platform revenue is mainly from the cost of railway oil users to platform. Considering the simplest way of charging, this paper supposes that the platform operators collect the minimum payment $I_{1}$ (Yuan/ton) from users with the usage amount of railway oil as measurement unit, and 
the annual usage amount of railway oil for the whole railway network is $Q$ (ton).

After the platform is put into operation, recovery of all investment cost within $T$ years is required. In the first $n_{0}$ years, the initial fixed costs will be put into. The next $n_{1}$ years, the operating costs will be put into in every year. $T=n_{0}+n_{1}$.

Calculate the investment recovery period of the information platform:

$$
T=\frac{\text { Total investment }}{\text { Annual net cash flow }}=n_{0}+\frac{S+n_{1} \cdot R}{\left(I_{1}+3\right) \cdot Q-R}
$$

Based on cost analysis, the lower limit of platform Pricing $I_{1}$ can be written as:

$$
I_{1}=\frac{S+2 n_{1} \cdot R}{n_{1} \cdot Q}-3
$$

(2) The determination of the upper limit of platform pricing based on the analysis of user benefits

Benefits of platform to users mainly include monetary and non-monetary benefits. Generally, the acquisition of monetary benefits is the key factor. In addition, reducing the time and energy expenditure can also increase the non-monetary benefits.

Benefits of the third party service platform of railway oil supply chain to users mainly include the monetary benefits brought by the reduction of the oil storage funds, shorten of management time, and the non-monetary benefits brought by the reduction of manpower and material resources and the reduction of environmental pollution. Among them, due to high oil price, the most important benefits for users are the monetary benefits brought by the reduction of the oil storage funds, shorten of management time.

Assuming that the platform financial settlement function has been successfully used, the reduction of the oil storage funds is $u$ million yuan. It is supposed that the railway bureau can use the direct benefits brought by the oil storage funds. So based on the analysis of the user benefits, platform service pricing should not exceed the benefits obtained by platform users.

The upper limit of platform pricing $I_{2}$ (Yuan/ton) can be written as:

$$
I_{2}=\frac{u \cdot \varphi}{Q}-3
$$

\subsection{Platform Negotiation Pricing Based on Bargaining Game.}

The third party service platform of railway oil supply chain is the information support to realize the integrated supply mode of railway oil. Its pricing determines the level of income of the platform, and indirectly affect the success of the reform of the railway oil supply mode. This paper adopts bargaining game to determine the optimal pricing [5, 6]. Model assumptions are as follows:

(1) Game participants are rational.

(2) The basis of bargaining game between the platform and the users is $\pi=I_{2}-I_{1}$.

(3) Platform pricing does not consider the competitive factors of other third party service platform of railway oil supply chain [1].

Because the platform operator occupies a leading position, odd round bid by the platform operator, and the platform users choose whether to accept. Even round bid by the platform users, and the platform operator choose whether to accept. It is supposed that $\delta_{\mathrm{S}}$ and $\delta_{\mathrm{C}}$ is the platform and the users' discount factor. $\delta_{S}, \delta_{\mathrm{C}} \in(0,1)$. The discount factor represents the loss of each round of negotiations and the bargaining power of the two parties.

The first round, platform bid $X_{1}$, and the user accepts, the unit oil surcharge logistics service platform is $P=I_{1}+X_{1}$, and the final user benefits for $\pi-X_{1}=I_{2}-\left(I_{2}+X_{1}\right)$.Conversely, if the user does not accept, then the user bid $X_{2}$, and so turns bidding until the first round of $\mathrm{n}$ and the end of the agreement, the first round of $n$ platform users and the actual earnings were $\delta_{S}{ }^{n-1} X_{n}, \delta_{n}{ }^{n-1}\left(\pi-X_{n}\right)$.

According to Mr Rubenstein Nash bargaining model the ultimate equilibrium results as follows: 


$$
X^{*}=\frac{1-\delta_{C}}{1-\delta_{S} \delta_{\mathrm{C}}} \pi
$$

At this point, the optimal unit pricing for the platform:

$$
P^{*}=I_{1}+X^{*}
$$

\subsection{The Case Analysis.}

The railroad industry oil supply chain third-party service platform operation related datais substituted into the platform service pricing model, can get the following results:

(1) Based on the cost analysis to determine the lower limit of the platform service pricing

Among them, in 2010 investment in fixed costs $S=80$ million yuan for the construction of the platform, At the end of 2014 the platform officially put into use of the whole railway network, so the platform construction of the national railway went into operation before the time for 5 years, according to 2014 data platform, a platform for operation and maintenance costs per year on average $R=8$ million yuan, assuming that the oil consumption of the whole railway network of about 5.5 million tons in 2014, then $Q=550$.

Assuming from the date of the construction platform, 20 years to recover all the investment, that is, $\mathrm{T}<20$ and $\mathrm{n}_{0}=5, \mathrm{n}_{1}=15$, into the type (1)

$$
I_{1}=\frac{S+2 n_{1} \cdot R}{n_{1} \cdot Q}-3=\frac{8000+2 \times 15 \times 800}{15 \times 550}-3=0.88 \text { yuan }
$$

(2) Based on the user benefit analysis to determine the upper limit of the platform service pricing According to research data shows that in 2014 the whole way users can save oil stock funds used about 1.2 billion yuan, that is $\mathrm{u}=120000$ million. Further, assume that $\varphi=2 \%$.

Then,

$$
I_{2}=\frac{u \cdot \varphi}{Q}-3=\frac{120000 \times 2 \%}{550}-3=1.36 \text { yuan }
$$

(3) Determine the platform service pricing feasible range

User oil per purchase 1 ton on the platform, platform service pricing possible price range of $[0.88,1.36]$ yuan.

(4) Negotiate pricing

By (3) the results can be obtained

$\pi=I_{2}-I_{1}=1.36-0.88=0.48$ yuan, according to the analysis of the negotiated pricing of the platform to build, the user's bargaining power will be slightly below the platform bargaining power, therefore, assuming that the platform and the user's discount factor respectively take $\delta_{\mathrm{S}}=0.8, \delta_{\mathrm{C}}=0.7$, into the formula (4): $X^{*}=\frac{\mathrm{l}-0.7}{1-0.7 \times 0.8} \times 0.48=0.33 y u a n / \mathrm{t}$.

User oil per purchase 1 ton on the platform, the platform service optimal pricing for $P^{*}=I_{1}+X^{*}=1.21$ yuan .

\section{Conclusion}

This article first determines the basis of information service platform for pricing, followed by analysis and user cost benefit analysis to determine the possible price range, and through the bargaining game model get the mutual negotiation pricing strategy. Finally, using the platform operating data for example analysis.

As the platform function gradually improve, platform will provide users with more and more value-added services, such as providing mobile access platform, carries on the key data of mobile phone review, SMS send important information, etc. Pricing for these value-added services will be the focus of future research. 


\section{Acknowledgment}

The paper is sponsored by National Science-technology Support Plan Projects "Research and Application of the Third Party Logistics Service Platform of Railway Oil Supply Chain” (No. 2014BAH23F02) and "Research of Real-time Monitoring, Tracing and Management Technology of Supply Chain Logistics” (No. 2014BAH23F01).

\section{References}

[1]. Zhang Dongya. Application Research on Railway Oil Supply Management Mode Transformation and Upgrading [J].Railway Purchase and Logistics. 2013(8):42-44.

[2]. Wu Xinghua. Research on Regional Logistics Information Platform Based on the Strategy of Incentive Stackelberg Game Toll Pricing [D].Beijing Jiaotong University.2010.

[3]. DuanMu and Yuncong. Research on Cloud Service Supply Chain Pricing Strategy [D].Nanjing .Nanjing University.2013:30-41.

[4]. Che Wenwen. Research on C2C E-commerce Platform Pricing Model and Earnings Impact Factors [D]. Shanghai.Shanghai Jiaotong University.2010.

[5]. Wang Shanshan. Bargain Game Theory Review [J].Science and Technology Economic Market.2006, 10: 167.

[6]. Mu Su and Guan Yiping. Bargaining Theory and Its Applications [M]. Shanghai. Shanghai University of Finance and Economics Press.2005. 